\title{
Language Development in Normal Libyan Children
}

\author{
ASMAA H. BOSHWISHA, M.Sc., AHMED N. KHATAB, M.D. and RASHA M. SHOEIB, M.D. \\ The Department of E.N.T., Phoniatric Unit, Faculty of Medicine, Ain Shams University, Cairo, Egypt
}

\begin{abstract}
Background: Language is central to social life; language development is a cornerstone for successful outcomes later in life. Language refers to the entire system of expressing and receiving information in a way that's meaningful. Language consist of four dimension, the sound system (phonology), the system of meaning (semantics), the rules of sentences formation (syntax) and function or use of language includes (pragmatics) that consists of the goals of language. The Language development is a complex, dynamic and progressive process. It involves detection of complex patterns and improvement of language competencies. Language development may affected by various factors as neurobiological factors, culture and psychosocial factors. Background history and formal testing are important in assess language development. Early intervention for language difficulties are very important also. The earlier language intervention is implemented, the better results will found.
\end{abstract}

Aim of Work: The aim of this study is to evaluate language development in normal Arabic Speaking Libyan Children in order to identify the normal developmental language aptitudes in such population.

Study Design: A descriptive research design was used to achieve the aim of this study.

Patients and Methods: The subject of this study comprised a convenient sample of 120 normal Arabic Libyan children with age range between 3 months and 7 years. Modified Arabic (PLS-4) Test, Articulation test Standford Binnia test and audiological evaluation were done for all children.

Results: The Standred score of Arabic PLS-4 was below normal (77.5) in of cases $(56.6 \%)$ while it was high in $(43.33 \%)$. Both receptive and expressive difficulties was found in $30 \%$ of children. A highly significant statistical correlation between total language age, receptive language age and expressive language age with chronological age was found. In addition, the study revealed that children more than 6 years and the children from 3-4 years have delayed in receptive language score, expressive language score and total language score regarding their chronological age.

Conclusion: The normal Arabic Libyan children was found to be delayed in language development in age groups

Correspondence to: Dr. Asmaa H. Boshwisha,

The Department E.N.T., Phoniatric Unit, Faculty of Medicine, Benghzia University, Benghzia Libya

E-Mail: Asmaahmad2006@ yahoo.com (more than 6y) and (3-4y) according to standred score in PLS4 . These result will be use to formulate a language aprofile for normal Arabic Libyan children.

Key Words: Language development - Language age difficulties - Receptive language - Expressive language Chronological age and Arabic PLS-4.

\section{Introduction}

HUMAN language is a form of sonic communication that exhibits remarkable structural complexity [1].Language can also be defined as the ability to produce practically infinite number of meaningful messages using a finite number of meaningful messages using a finite number of lexical items (2).

Language refers to the entire system of expressing and receiving information in a way that's meaningful [3]. Language consist of four dimension, the sound system (phonology), the system of meaning (semantics), the study of grammar (structure) morphology and syntax, the study of language use (pragmatic) [4]. The phonological structure is divided in to levels: The segmental and suprasegmental levels. The segmental level is related to language sounds which are either vowels or consonants. The supra-segmental is the prosody of language. Semantics refers to the expression of meaning in language and is differentiated from underlying concepts or categories. Morphemes are the minimal level units of meanings either words (free morphemes) or meaningful parts of words (bound morphemes). Syntax refers to sentences patterns and the arrangement of words represents relation between them [5]. Pragmatics is the set of rules that govern the use of language in a certain context $[4,5]$.

The process by which humans acquire the capacity to perceive and comprehend language, as well as to produce and use words and sentences to communicate is called Language acquisition [6] 
Several theories and approaches have emerged over the years to study and analyze the process of language acquisition as Inmates theory, Learning theories and Mixture theory [7]. The Language development is another important concept. It is a complex, dynamic and progressive process. It involves detection of complex patterns and improvement of language competencies [8]. Receptive and expressive skills are considered the most important skills in describing of language in children. The receptive skill is always in advance of expressive skill [9].

Prerequisite Skills for normal Language development include: Intact brain function, normal sensory channel (visual, auditory skills, kinesthetic and tactile skills), Intact psychological stat and environmental role $[\mathbf{1 0 , 1 1 ]}$.

Up to 3 months the child's listening and attention turns towards a familiar sound and startled by loud noisy, they recognizes parent's voice and often calmed by familiar friendly voice [12] . From 4-8 months (vocal play) At this stage, the child's has more control on his vocal tract so he can manipulate loudness and pitch range. Its is characterized by repetitive vowel like sound [13] the child from 610 months (Reduplicated babbling), usually starts suddenly around age 6 months and extends till baby's first words which appear at age of 12 months [14]. In addition, from 12-15 months, the children at this stage says around 10 single words. They understand single words in contex, understands more words than they can say, understand simple instructions, produce protoword ie invented words that are used consistently to express specific meaning, but that are not real words in children starget languag [15]. In 15-18 month, At this stage children produce single words: Nouns, action words and at the end of this stage, two utterances appear: Single word succession, 2-word sentences. But sentences are structurally and functionally incomplete [16]

From 18 months to 2 years, children understand of single words develops rapidly during this stage and production ability is about 50 words which greatly differ from their perception ability as they can understand about 200 words [17] from 2-3 years: There is re markable increase in vocabulary size at this stage and it is called vocabulary or word spurt they developing understanding of simple concept including in/on/under [18]. During the stage from 3-4 years the speech of child should be completely intelligible, in spite of articulation problems, should be able to repeat sentences as long as nine word, Asking What, Where, Why, When and How questions, using 3-4 words in a sentence understand turn taking as well as sharing with adults and peers [18].

At 4-5 years the child can use well formed sentences, able to follow simple story without pictures and understands instructions containing sequencing words; 'first... after... last' [14] . At the age of 5-6 years the child understands more complicated sentences, the child can talking about past and future events. He learn more words and start to understand how the sounds within language work together also become a better story teller [19]. From 6-7 years they using language at a higher level to make jokes, sarcasm, explaining complex situation and asking question to clarify information [16].

\section{Subjects and Methods}

This study was carried out in Libyan school and nurseries on 120 normal Arabic Libyan children with age range between 3 months and 7 years in the period from July 2017 till January 2018. The children were considered eligible to participate in the study if they met the following criteria:

- Native Arabic Libyan speakers.

- IQ 90 or above.

- Parents of children have lived in Libya since birth.

- Colloquial Arabic as first language.

- Normal hearing and vision.

\section{Exclusion criteria include:}

- Any disorders affect language development.

- Children exposed to more than one language.

\section{Procedures and clinical tools:}

For assessment of children, the following selected assessment steps, extracted from the language assessment protocol that is structured and used at the Unit of Phoniatrics Ain Shams University was used:

- Patient interview and case history taking including child name, age, sex.

- General examination to exclude any neurodevelopmental disorders.

- Mental status examination by psychometric test (Standford Binnia) [22] to provide mental age, in order to exclude any mentally subnormal children.

- Language testing by Modified PLS-4 test Arabic edition [20]

- The Arabic Ain Shams Articulation test [21].

- Audiological assessment. 
Language testing by modified Arabic (PLS-4) test: [20] PLS-4 Arabic edition is standardized language test, which was standardized on normal Arabic speaking Egyptian children. It is used mainly to identify children who have a language disorders or delay. It composed of two main subscales:

- Auditory comprehension (AC) or receptive subscale (it contained of 62 items. Certain items contain several practices or criteria that the child must fulfill. These items act as an important precursor for language development. The practices were also divided according to the child age.

- Expressive comprehension (EC) subscale include items that the expression of vocal development. Social communication, quantity, use of specific proposition, grammatical markers and telling a short story. It contained of 77 items. Certain items contain several practices or criteria that the child must fulfill.

\section{Standard score:}

The examiner depends mainly on the total language standard score to determine if the child's language is normal or delayed. Total language standred score is 77.5. Score less than 77.5 indicates language difficulties. The researcher tries to translate the test into Libyan language to facilitate children understanding of questions and sentences.

\section{Arabic articulation test:}

The Arabic Ain Shams Articulation test was applied to all verbal children with language abilities adequate enough to undergo the test. Test cover all phonemes in different positions (initial, middle, final) of words through picture naming. The affected phoneme and phonemic process was discovered and noted.

Psychometric evaluation: It was used to assess the mental age and intellectual quation (IQ), it must be 90 or more.

Audiological evaluation: Was used to assess the child hearing ability. The children normal hearing level ranged from $10-15 \mathrm{~dB}$. This level reflects that there is no hearing disorder encountered.

\section{Results}

The study was based on 120 normal Libyan children with age range between the age of 3 months and 7 years.

$63(52.5 \%)$ of the participants were male, while $57(47.50 \%)$ of the participants were females as shown in Fig. (1).

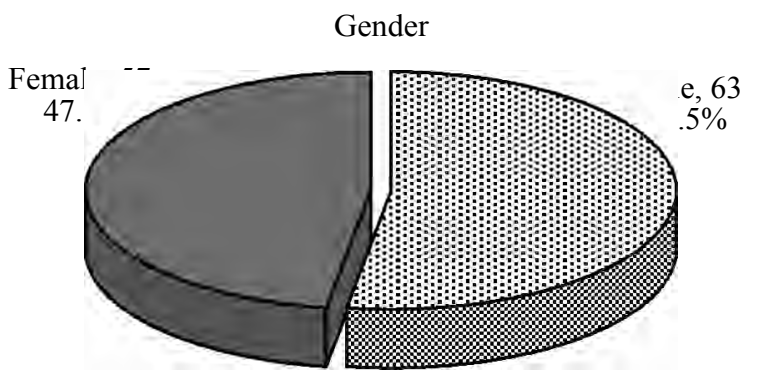

Fig. (1): Gender distribution in study group $(n=120)$.

The sex distribution of the sample for each age group is shown in Table (1).

Table (1): Distribution of gender according to chronological age group $(n=120)$.

\begin{tabular}{lllllll}
\hline \multirow{2}{*}{$\begin{array}{l}\text { Che } \\
\text { age }\end{array}$} & \multicolumn{2}{c}{ Female } & \multicolumn{2}{c}{ Male } & \multirow{2}{*}{ Total } & $\%$ \\
\cline { 2 - 5 }$<1 \mathrm{y}$ & No. & $\%$ & No. & $\%$ & & \\
\hline $1-2 \mathrm{y}$ & 7 & 53.8 & 6 & 46.2 & 13 & 10.83 \\
$2-3 \mathrm{y}$ & 12 & 44.4 & 15 & 55.6 & 27 & 22.50 \\
$3-4 \mathrm{y}$ & 5 & 41.7 & 7 & 58.3 & 12 & 10.00 \\
$4-5 \mathrm{y}$ & 5 & 45.5 & 6 & 54.5 & 11 & 9.17 \\
$5-6 \mathrm{y}$ & 4 & 40.0 & 6 & 60.0 & 10 & 8.33 \\
$>6 \mathrm{y}$ & 13 & 59.1 & 9 & 40.9 & 22 & 18.33 \\
\hline Total & 11 & 44.0 & 14 & 56.0 & 25 & 20.83 \\
\hline
\end{tabular}

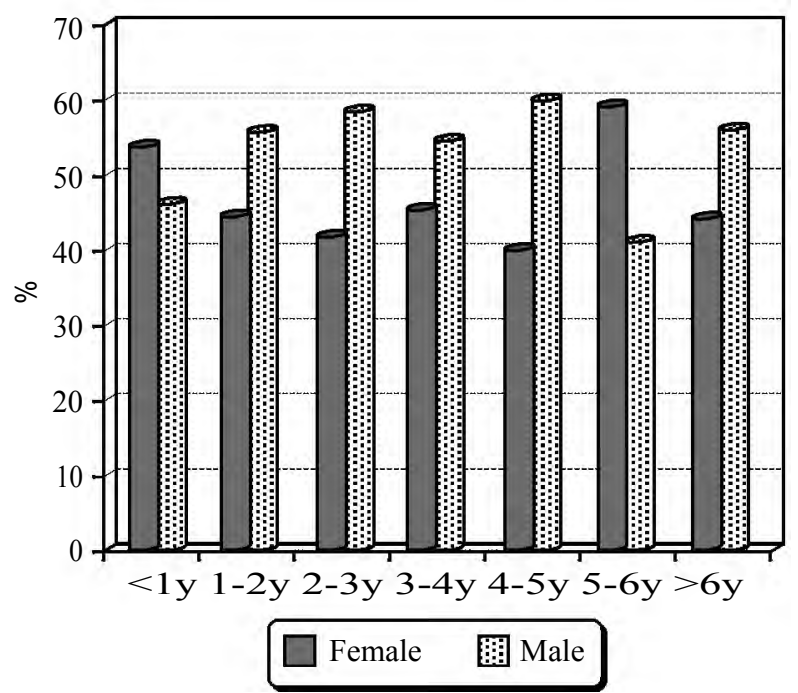

Fig. (2): Simple bar chart which represents percent of males and females in the study group.

A total number of 120 children were classified according to age into 7 age groups as shown in Fig. (3). 


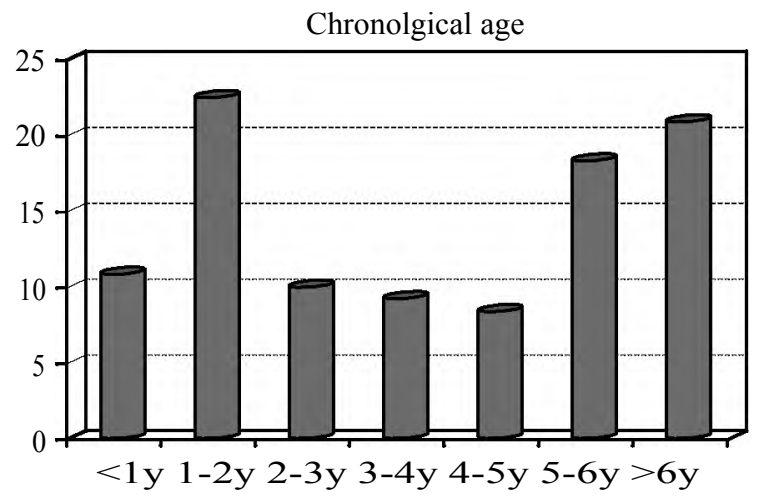

Fig. (3): Chronological age distribution in study group.

This figure shows standred score (normal $=77.5$ ): Large number of sample was below standred score in $56.67 \%$ while above standred score in $52.43 \%$.

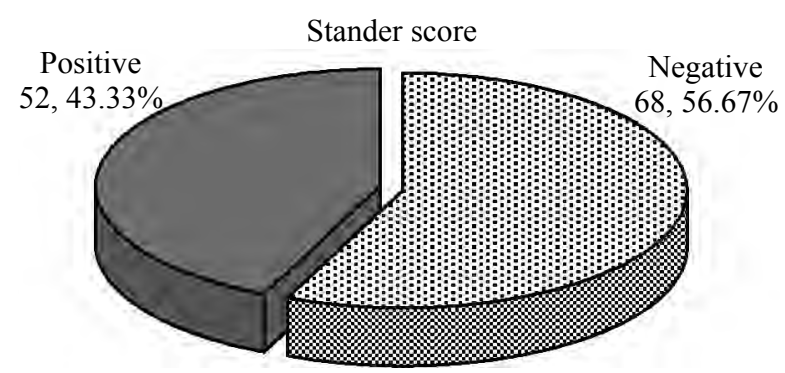

Fig. (4): Stander score distribution in study group $(n=120)$.

Regarding the relation between receptive language and chronological age, the highest value by mean and standard deviation of receptive language at age of more than 6 years with $(72.506 \pm 17.457)$ and age of $4-5$ years with $(71.423 \pm 13.831)$ followed by age of $3-4$ years with $(66.093 \pm 12.615)$, the lowest value by mean and standard deviation of age less than one year with $(71.749 \pm 6.178)$. This table shows highly significant statistical correlation between receptive language and chronological age. That's indicate receptive language score less than chronological age in children $>6 y, 3-4 y$ as shown in Fig. (5).

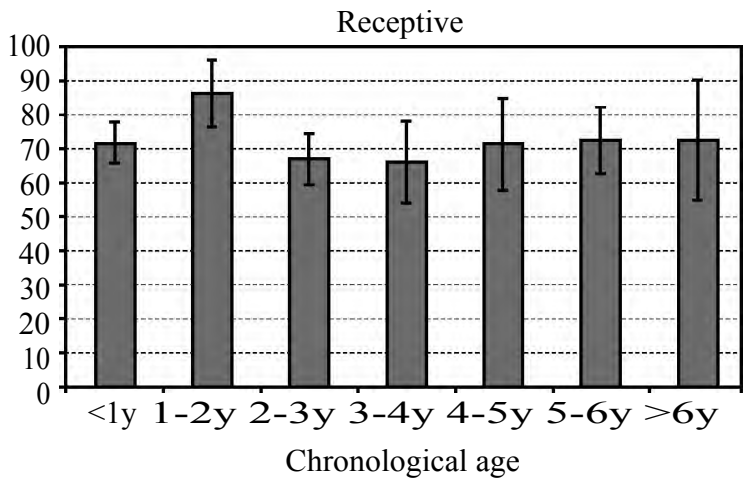

Fig. (5): Thecorrelation between Receptive language and Chronological age.
Regarding the relation between expressive language and chronological age, the highest value of mean and standard deviation were observe at age of more than 6years with $(70.888 \pm 13.815)$ and age of 3-4 years with $(66.093 \pm 12.615)$ followed by age of 4-5 years with (70.732 \pm 8.755$)$, the lowest value by mean and standard deviation were observe at age of less than one year with $(70.921 \pm 5.611)$. This table shows highly significant statistical correlation between expressive language and chronological age. That's indicate expressive language score less than chronological age in children $>6 y$, $3-4 y$ as shown in Fig. (6).

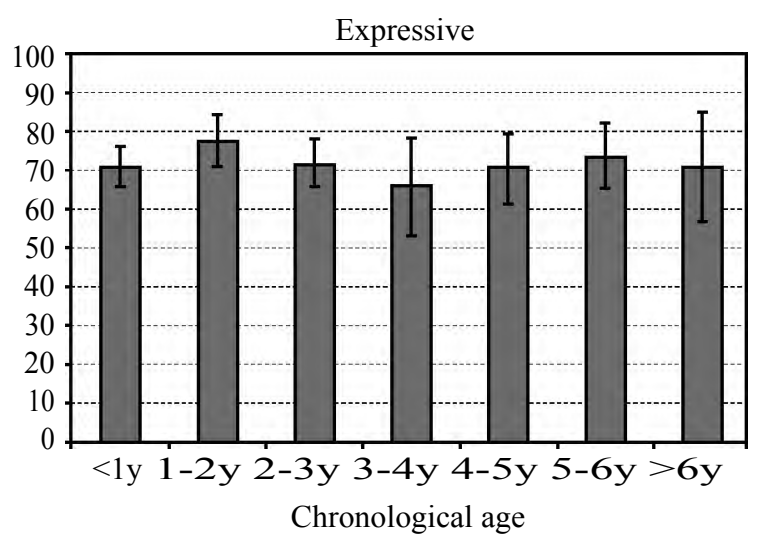

Fig. (6): The corr elation between Expressive language and Chronological age.

Regarding the relation between total language and chronological age, the highest value by mean and standard deviation of age more than 6 years with $(71.426 \pm 13.692)$ and age of $3-4$ years with $(66.093 \pm 12.615)$ followed by age of $4-5$ years with (71.032 \pm 11.055$)$, the lowest value by mean and standard deviation of age less than one year with (71.591 \pm 5.248$)$. This table shows highly significant statistical correlation between total language and chronological age that's indicate total language score less than chronological age in children $>6 y$, $3-4 y$ as shown in Fig. (7).

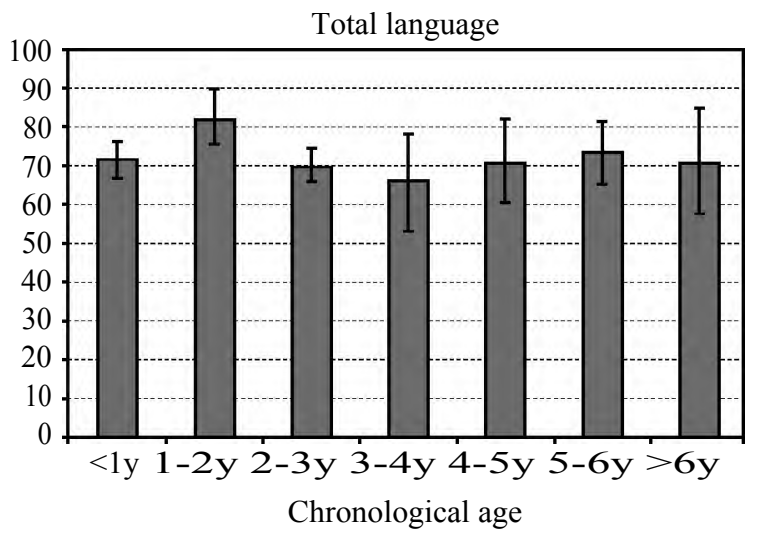

Fig. (7): Thecor relation between total language and Chronological age. 


\section{Discussion}

Language is central to social life; language development is a cornerstone for successful outcomes later in life. A child language and speech abilities grow according to their need to use it,their interests, and the meaning it has for them language acquisition is fostered bypositive interaction regarding language between the child and an aduit.it is important to know that language develops in early childhood, and preschool age. The sample of this study was based on 120 normal children between the age of 3 months and 7 years. The highly significant statistical correlation between total language age, receptive language age and expressive language age with chronological age where Receptive language, expressive languge, total language score was delay regarding to chronological age Cho et al., [23]. Supported this result they reported that there is delayed in receptive and expressive language in their sample regarding to their chronological age. On another study Kim et al., 2011 [24] reported that the receptive language was better than expressive language function in their sample.

In this study the results revealed that,children more than 6 year and the children from 3-4 years have delayed in receptive language, expressive language and total language regarding their chronological age. This results congruent with the results of Gad-Allah et al., [25] in their study entitled with "Identification of communication disorders among Egyptian" they demonstrated that about one third of the studied children had delayed language, On the other hand, Somefun et al. [26] reported that $70 \%$ of preschool Nigerian children who referred to Lagos University Teaching Hospital had delayed language A closer look to the distribution of different types of delayed language developed children according their socio-demographic data, we found that most of them have no apparent cause.

In receptive language problems, the child comprehension is decreased and he/she speaks with an unclear and sparse use of words and has a problem connecting words with directions, such as pointing at an object or carryout instructions [27] Heidi, Feldman [28] explain in his result that most of his sample of preschool children had delayed in receptive language according to their receptive age this results on a line with our study results which revealed that there is delayed in receptive language regarding receptive age.

Regarding expressive language problems a child thinks and understands clearly and develops normal relationships, but he or she has problems effectively utilizing expressive language versus basic talking [25]. In this study there is delayed in expressive language score in related to chronological age. This result is found mostly in age more than 6years and age of 3-4 years. This may be resulted from the impact of the ware on the social life and communication manner among people.

Children may be cannot express themselves according to their age may be for many reasons as providing a vast of cartoon films which affect the linguistics expressions of children in addition to the nature of modern life which have daily stressors affects the children and their families communication. This result was in agreement with Noel (2007) [29] who studied the effect of parent stress on their children temperament and found that parent stress affects their children language as parenting stress was related to children's receptive and expressive vocabulary skills.

\section{Conclusion and recommendations:}

The present study was an attempt to evaluate language development in normal Arabic Speaking Libyan Children in order to identify the normal developmental language aptitudes in such population. Results of this study showed highly significant statistical correlation between total language age, receptive language age and expressive language age with chronological age in addition, the study revealed that children more than 6 year and the children from 3-4 years have delayed in receptive language score, expressive language score and total language score regarding their chronological age. After application of modified PLS-4 on the Libyan Arabic Children we can conclude that, the Libyan profile is delayed to Egyption profiles, but for some elements in which their acquisition was similar while language difficulties highlighted by this study, a lot nevertheless remains to be studied. Further research is particularly needed to explore how traditional beliefs, practices, and indigenous knowledge of mothers regarding children language development, and caring for children with language difficulties. Further studies needed on a larger sample and another culture in order to compare and generalize the findings.

\section{References}

1- ROHRMEIER D.M. and SAMELLI A.G.: Association between audioloical profile and primary language impairment, 2015 .

2- ARSHAVSKY Y.I.: Two function of early language experience. Brain Res. Rev., 60 (2): 327-4, 2009.

3- Connecticut State Department of Education: A Blueprint for School Speech and Language Services in Connecticut: 
A Report of the School Speech and Language Forum. Hartford, 2006.

4- LANGDON H.W.: Interpreters and Translators in Communication Disorders: A Practitioner's Handbook. Eau Claire, WI.: Thinking Publications, 2002.

5- MARY E.: Dahlgren Oral Language and Vocabulary Development Kindergarten \& First Grade 2008 mdahlgren1@yahoo.com

6- MILLER S., JUNGHEIM M. and PTOK M.: First language acquisition research and theories of language acquisition. HNO, 62 (4): 242-8, 2014.

7- WARREN J.: The Cognitive Learning Theory. Retrieved from http:/jwar.edublogs.org/2012/07/11/the-cognitivelearning-theory, 2012.

8- BLOOM L. and TINKER E.: The intentionality model and language acquisition. Monographs of the Society for Research in Child Development, 66 (4), 2001.

9- RICHLER J., HUERTA M., BISHOP S.L. and Lord C.: Developmental trajectories of restricted and repetitive behaviors and interests in children with autism spectrum disorders. Development and Psychopathology, 22: 55-69, 2010.

10- GILBERT C. and FOSTER A.: Childhood blindness in the context of VISION 2020.The right to sight.Bulletin of the World Health Organization, 79 (3): 227-232. PMID: 11385667,2001

11-GARFINKLE A.N. and SCHWARTZ I.S.: Peer imitation: Increasing social interactions in children with autism and other developmental disabilities in inclusive preschool classrooms.Topics in Early Child Special Education, 22: 26-38, 2002.

12- HOFF E.: Language development. ${ }^{{ }^{\text {thed. }}}$ Belmont, CA: Wadsworth Cengage Learning, 2009.

13- TAKAHASHI D.Y., FENLEY A.R. and GHAZANFAR, A.A.: Language Development. The developmental dynamics of marmoset monkeyvocal production. Science, 14; 349 (6249): 734-8, 2015.

14- CONTI-RAMSDEN G. and DURKIN K.: Language development and assessment in thepreschool period. Neuropsychol. Rev., 22 (4): 384-401, 2012.

15- de DIEGO-BALAGUER R., MARTINEZ-ALVAREZ A. and PONS F.: Temporal Attention as a Scaffold for Language Development. Front Psychol., 2 (7): 44, 2016.

16- PLEJERT C. and SMUELSSON C.: Language development in normal children and in Disease An Interactional Approch to Typical Language Development and children with language impairment, 2012.
17- UKREINETZ T.: Contextualized language Intervention. Greenville S.C. :Thinking Publication, 2007.

18-ZIMMERMAN I.L., STEINER V. and POND R.: Preschool Language Scale-4th Edition. San Antonio, TX: Harcourt Assessment. Introduction, 2002

19- FLUSBERG H.: Language acquisition, Encyyclopedia of the Human Brain. Academic Press, 2: 617-627, 2002.

20- ABO HASIBA A.: Standardization, Translation andModification of the Preschool language Scale-4 Ph.D. Dissertation. Ain Shams Univerisity, 2002.

21- KOTBY M.N., BASSIOUNY S., EL-ZOMOR M. and MOHSER E.: Pilot study for standardization of an articulation test Published in Proc 10 th Annual AinShams Medical Congress, Cairo, 1985 right to sight. Bulletin of the World Health Organization, 79 (3): 227-232. PMID: $11285667,1985$.

22- Standford Binnet Intelligence Scale 5 th Arabic version: (Melika, 1988): Standardization intelligence test IQ.

23- CHO S.R., PARK E.S., PARK C.I., KWAK E.H., KIM M.K., MIN K.H., et al.: Relationship of language, intelligent and social quotients in children with speech and language disorder. J. Korean Acad. Rehabil Med., 32: 129-134, 2008.

24- KIM S.W., SHIN J.B., BAE M.S., CHUNG H.J., KIM Y.K. and SONG J.H.: Effects of speech therapy in children with specific language impairment and mild intellectual disability. J. Korean Acad. Rehabil Med., 35: 48-54, 2011.

25- GAD-ALLAH A., SAMAR ABD-ELRAOUF A., Tamer ABOU-ELSAAD B. and MAHASSENABD-ELWAHED C.: Identification of communication disorders among Egyptian Arabic-speaking nursery schools' children Egyptian Journal of Ear, Nose, Throat and Allied Sciences, 13: 83-90, 2012.

26- SOMEFUN O., LESIE F. and OLUSANYA B.: Communication disorders in Nigerian children. Int. J. Pediatrotorhinolaryngol., 70 (4): 697-702, 2006.

27- GASKELL M.G. and ELLIS A.W.: Word learning and lexical development across the lifespan. Philos Trans R Soc. Lond B Biol. Sci., 364 (1536): 3607-15, 2009.

28- HEIDI M. FELDMAN: Language and Speech Disorders Advanced Research, 4: 717-729, 2009.

29- NOEL M., PETERSON C. and JESSO B.: The relationship of parenting stress and child temperament to language development among economically disadvantaged preschoolers. J. Child Lang, 35: 823 843, 2008. 


\section{تطوير اللغة فى أطفال ليبيا الطبيعيين}

اللغة البشرية هى شكل من الاتصالات الصوتية المعقدة ولها هيكل محدود وثيابت وبتكون من القواعد التى تربط بعض الرموذ الخاصة من كلمات وجمل لمعانى معينة.

اللغة عبارة عن رموذ صوتية لها نظم متوافقة فى التركيب والألفاظ والأصوات وتستخدم هن أجل الاتصال والتواصل الاجتماعى والفردى

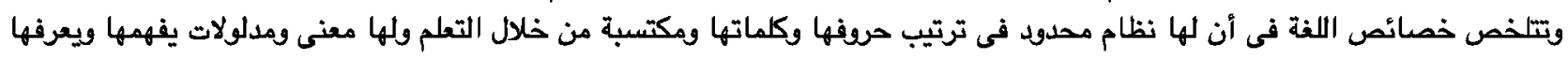
السامع والمتصدث.

وتقدم هذه الرسالة معلومات عن التطود الطبيعى اللغة فى الأطفال الليبيين الطبيعيين لمعرفة تطود اللغة الطبيعى لهذه الفئة وذلك لاستخدامها

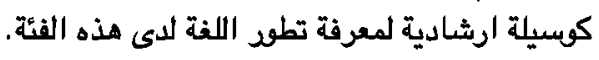

الهدف من الرسالة هو تقييم تطود اللفة الطبيعى فى الأطفال الليبيين المتحدين بالعريية لمعرفة تطود اللفة الطبيعى لهذه الفئة.

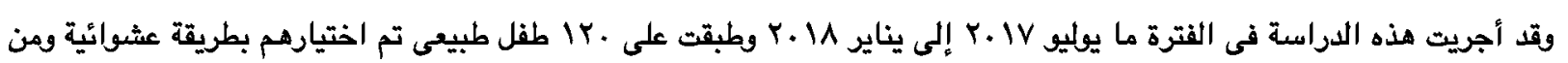

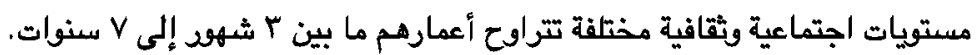

الأطفال الذين سيشاركون فى هذه الدراسة لابد أن يكونوا متحدثين باللغة العربية، معامل الذكاء ـ9 أو أعلاه، اللهجة الليبية هى (اللغة الأم)، أن يكن السمع والنظر طبيعى ومحل آقامة الوالدين ليييا هن الولادة. 